\title{
INDICATIVOS DE ALTAS HABILIDADES E SUPERDOTAÇÃO DE ALUNOS DO ENSINO FUNDAMENTAL DO NRE DE UMUARAMA - PR
}

Arnaldo Gomes do Amaral ${ }^{1}$ Rosangela Bressan Buosi ${ }^{2}$ Herica Hellen de Souza ${ }^{3}$ Alana Gabriela Rodrigues ${ }^{4}$

AMARAL, A. G. do; BUOSI, R. B.; SOUZA, H. H. de; RODRIGUES, A. G. Indicativos de altas habilidades e super dotação de alunos do ensino fundamental do nre de Umuarama - Pr. EDUCERE - Revista da Educação, Umuarama, v, 7, n. 2, p. 307-xxx, jul./dez. 2017.

RESUMO: O projeto visa a obtenção de informações sobre a quantidade de alunos com indicação de diagnóstico de altas habilidades e superdotação das Escolas Estaduais de Umuarama e Região, indicadas para a utilização de sala de Recursos Multifuncional - Tipo 1- específico para alunos com altas habilidades e superdotação. E a verificação da disponibilidade destas salas para o atendimento dos referidos alunos avaliados como altas habilidades e superdotação. Os dados foram coletados através de pesquisa em documentos consultados no Núcleo Regional de Educação de Umuarama, constam dados de 14 cidades e 53 colégios, obtendo 204 alunos indicados para diagnóstico de AH/SD.

PALAVRAS-CHAVE: Inclusão; Sala de Recurso Multifuncional - Tipo 1.

\section{INDICATION OF HIGH SKILLS AND GIFTEDNESS OF STUDENTS OF THE FUNDAMENTAL EDUCATION IN THE UMUARAMA NRE - PR}

\footnotetext{
ABSTRACT: The project aims to obtain information regarding the num-

DOI: $10.25110 /$ educere.v17i2.2017.6604

${ }^{1}$ Mestre em Ciência da Computação - Professor da UNIPAR Sede - Universidade Paranaense.

E-mail: arnaldo@unipar.br

${ }^{2}$ Mestre em Educação - Professora da UNIPAR Sede - Universidade Paranaense.

E-mail: robressan@unipar.br.

${ }^{3}$ Acadêmica do Curso de Pedagogia - PIC/UNIPAR

${ }^{4}$ Acadêmica do Curso de Pedagogia - PIC/UNIPAR
} 
ber of students with indication of high skills and giftedness of the State Schools of Umuarama and Region, referred to use a Multifunctional Resource Room - Type 1, which is specific for students with high skills and giftedness. It will also assess the availability of those rooms for receiving such students considered as presenting high skills and giftedness. Data were collected through document research at the Regional Education Center in Umuarama, where it houses documents from 14 cities and 53 schools, obtaining 204 students referred to be diagnosed with HS/G. KEYWORDS: Inclusion; Multifunctional Resource Room - Type 1.

\section{INDICATIVOS DE ALTAS HABILIDADES Y SUPER DOTACIÓN DE ALUMNOS DE LA ENSEÑANZA FUNDAMENTAL DEL NRE DE UMUARAMA - PR}

RESUMEN: El proyecto busca la obtención de informaciones sobre la cantidad de alumnos con indicación de diagnóstico de altas habilidades y superdotación de las Escuelas Estaduales de Umuarama y Región, indicadas para la utilización de aula de Recursos Multifuncional Tipo 1- específico para alumnos con altas habilidades y superdotación. También verificación de disponibilidad de estas aulas para la atención de dichos alumnos diagnosticados. Los datos fueron recolectados a través de investigación en documentos consultados en el Núcleo Regional de Educación de Umuarama, constando datos de 14 ciudades y 53 colegios, obteniendo 204 alumnos indicados para diagnóstico de AH / SD.

PALABRAS CLAVE: Inclusión; Aula de Recurso Multifuncional - Tipo 1.

\section{INTRODUÇÃO}

Este trabalho justifica-se pela necessidade de realizar um levantamento entre as escolas estadual de Ensino Fundamental, sobre a quantidade de alunos com indicativos de diagnóstico de altas habilidades e superdotação, uma vez que no sistema de ensino se dá muita ênfase nos problemas de aprendizagem como transtornos globais de desenvolvimento e transtornos funcionais específicos entre outros, em detrimento as dificuldades de aprendizagem apresentadas por alunos com altas habilidades e superdotação, que em muitas vezes estes alunos não são encaminhados, nem mesmo para o primeiro diagnóstico, ficando discriminados, estig- 
matizados como alunos indisciplinados ou desinteressados no ambiente escolar. E quando diagnosticado observa-se, que poucas são as oportunidades educacionais oferecidas ao aluno com altas habilidades e superdotação para desenvolver de forma mais plena as suas habilidades. Uma possível explicação para este cenário são os vários mitos sobre o superdotado, frequentes em nossa sociedade, que constituem entraves provisão de condições favoráveis à sua educação.

Diante desse quadro se torna urgente identificar os alunos com altas habilidades e superdotação para realizar os encaminhamentos pedagógicos necessários ao desenvolvimento de suas habilidades específicas.

O processo de identificação dos alunos com altas habilidades e superdotação, é um trabalho realizado pela equipe da Educação Especial do NRE de Umuarama, que obtém as primeiras informações juntos as Escolas pertencentes a sua jurisdição.

O objetivo da pesquisa é verificar junto ao Núcleo Regional de Educação o número total de alunos com indicação de diagnóstico de altas habilidades e superdotação das Escolas Estaduais de Umuarama e Região, verificando o total de alunos indicados para o diagnóstico, quantas avaliações foram realizadas e quantos alunos foram confirmados com altas habilidades e superdotação, qual o número de alunos diagnosticados que estão frequentando as Salas de Recursos Multifuncional Tipo 1 - específico para alunos com altas habilidades e superdotação, e o número de salas de Recursos Multifuncionais -tipo 1 - específico para alunos com altas habilidades e superdotação. A pesquisa foi realizada através de pesquisa documental para verificar os registros de alunos indicados para o diagnóstico de AH/SD com a Chefia do Núcleo Regional de Educação, - Umuarama. Para autorização da pesquisa, análise de documentos e assinatura do Termo de Utilização de dados. Foi solicitado ao Departamento de Educação Especial, a relação de alunos com indicativo de diagnósticos de altas habilidades e superdotação para o levantamento do número total de alunos com indicativos de altas habilidade e superdotação. Foi verificado que do total de alunos indicados para diagnóstico, qual a quantidade de diagnóstico foram realizados pelo NRE e quantos alunos foram confirmados com altas habilidades e superdotação e quais escolas possuem sala de Recursos Multifuncionais específicas para o atendimento de alunos com altas habilidades e supordetação os mesmo foram encaminhados. 


\section{ALTAS HABILIDADES NA VISÃO DE ALGUNS AUTORES}

Ao longo da história, as pessoas que se sobressaiam em alguma habilidade, receberam vários nomes, como talentosos, capacidade elevada, bem dotados, entre outros. Na Legislação Brasileira, desde 1971 tem sido empregado o termo superdotado. Esse termo leva a entender a presença de um talento em uma área específica, seja na música, artes plásticas, na área literária, nas ciências exatas, ou em outras áreas. $\mathrm{O}$ comum nas diversas versões do termo é a presença de um desempenho elevado em uma área e/ou aptidões superiores.

A definição que está descrita no Parecer 17/2001 do MEC/SEESP apresenta altas habilidades/superdotação como sendo:

"grande facilidade de aprendizagem que os leve a dominar rapidamente os conceitos, os procedimentos e as atitudes e que, por terem condições de aprofundar e enriquecer esses conteúdos devem receber desafios suplementares em classe comum, em sala de recursos ou em outros espaços definidos pelos sistemas de ensino, inclusive para concluir, em menor tempo, a série ou etapa escolar." (BRASIL, MEC/SEESP, 2001, p. 39).

Erroneamente, essa terminologia traz consigo uma conotação de dom, de algo pronto e acabado que não precisa se estimulado ou desenvolvido. Estudando os fundamentando de Vigotski, entendemos que o ser humano, só se torna humano convivendo com outros seres humanos e aprendendo todo legado histórico e cultural que esses construíram ao longo da história da humanidade. De nada adianta uma criança ter um QI superior ao das outras pessoas, se ela não estiver imersa na cultura de seus pares. Por exemplo, uma pessoa só vai saber se tem dom e/ou habilidade para tocar um instrumento musical, se este lhe for apresentado. Dessa maneira, as habilidades de qualquer pessoa só são desenvolvidas no entrelaçamento das condições biológicas, culturais e históricas, em um processo de aprendizagem mediada socialmente pelos seres da mesma espécie.

Guenther (2000) conceitua as pessoas com altas habilidades / superdotação como crianças normais, igual às outras, as diferenças ficam 
por conta dos fatores culturais aos quais estão inseridas. Juntando-se a isso características relacionadas ao talento: vivacidade mental, automotivação e confiança. Para a autora, vivacidade mental está intrinsecamente ligada à curiosidade, ao enfrentamento de desafios, bom senso de humor, boa memória, ao domínio de uma gama muito grande de informação e conhecimento de mundo, a aprender com facilidade de diversas maneiras. A automotivação está relacionada à independência, a não ir pela opinião dos outros, persistência, compromisso com os deveres, motivação interna, aceitar a correr riscos, iniciativa, responsabilidade e participativas.

Algumas características da Superdotação e possíveis problemas:

\begin{tabular}{|l|l|}
\hline \multicolumn{1}{|c|}{ CARACTERÍSTICAS } & \multicolumn{1}{c|}{ POSSÍVEIS PROBLEMAS } \\
\hline Perfeccionismo & $\begin{array}{l}\text { Expectativas pouco realistas e muitas } \\
\text { horas de trabalho com baixa produti- } \\
\text { vidade }\end{array}$ \\
\hline $\begin{array}{l}\text { Pensamento crítico elevado, em rela- } \\
\text { ção a si próprio e aos demais }\end{array}$ & $\begin{array}{l}\text { Intolerante ou crítico dos demais, } \\
\text { pode tornar-se desencorajado, depri- } \\
\text { mido }\end{array}$ \\
\hline $\begin{array}{l}\text { Hipersensibilidade do sistema nervo- } \\
\text { so }\end{array}$ & $\begin{array}{l}\text { Hiperatividade e distração que levam } \\
\text { a déficits de atenção }\end{array}$ \\
\hline Iniciativa e autosuficiência & $\begin{array}{l}\text { Tendência em dominar as discussões } \\
\text { e atividades }\end{array}$ \\
\hline $\begin{array}{l}\text { Poder de concentração e comporta- } \\
\text { mento dirigido para metas }\end{array}$ & $\begin{array}{l}\text { Resistência a interrupções, negligen- } \\
\text { cia tarefas ou pessoas, obstinação }\end{array}$ \\
\hline $\begin{array}{l}\text { Avançadas estratégias de análise e re- } \\
\text { solução de problemas, percepção de } \\
\text { relações complexas entre ideias e fa- } \\
\text { tos, originalidade e criatividade }\end{array}$ & $\begin{array}{l}\text { Visto pelos outros como fora de com- } \\
\text { passo. Pensamento divergente, provo- } \\
\text { cando em seus pares discriminação e } \\
\text { rejeição }\end{array}$ \\
\hline $\begin{array}{l}\text { Rapidez na aquisição e retenção de } \\
\text { informações }\end{array}$ & $\begin{array}{l}\text { Impaciência com a lentidão dos cole- } \\
\text { gas, não gosta de rotina nem repetição }\end{array}$ \\
\hline $\begin{array}{l}\text { Aprendizagem eficiente, boa memó- } \\
\text { ria, e capacidade de observação }\end{array}$ & $\begin{array}{l}\text { Desenvolvimento de hábitos impro- } \\
\text { dutivos de trabalho, pouca dedicação } \\
\text { e interesse em buscar novas estraté- } \\
\text { gias de resolução de problemas, e bai- } \\
\text { xo rendimento acadêmico }\end{array}$ \\
\hline
\end{tabular}




\begin{tabular}{|l|l|}
\hline $\begin{array}{l}\text { Ampla base de conhecimentos, am- } \\
\text { plas informações em áreas avançadas }\end{array}$ & $\begin{array}{l}\text { Tédio em relação à escola e aos cole- } \\
\text { gas, visto pelos outros como o "sabe- } \\
\text {-tudo" }\end{array}$ \\
\hline Curiosidade, atitude questionadora & $\begin{array}{l}\text { Faz perguntas que incomodam o pro- } \\
\text { fessor }\end{array}$ \\
\hline Independência e inconformismo & $\begin{array}{l}\text { Repulsa por uma estrutura rígida de } \\
\text { aula, rebeldia, rejeita o que é imposto } \\
\text { pelos pais, educadores e pares }\end{array}$ \\
\hline $\begin{array}{l}\text { Sensibilidade e intensidade emocio- } \\
\text { nais, desejo de ser aceito }\end{array}$ & $\begin{array}{l}\text { Sensibilidade em relação às críticas } \\
\text { ou rejeição, sente-se diferente, alie- } \\
\text { nado }\end{array}$ \\
\hline Grande senso de humor & $\begin{array}{l}\text { Podem revelar-se sarcásticos e ofen- } \\
\text { der aos que estão próximos }\end{array}$ \\
\hline
\end{tabular}

Fonte: http://portal.mec.gov.br/seesp/arquivos/pdf/altashab2.pdf

$\mathrm{O}$ atendimento educacional deve ser realizado nas Classes de Ensino Regular comum com apoio especializado na Sala de Recursos Multifuncional Tipo I em período de contraturno. No entanto, esta sala tem uma característica diferente das outras salas de recursos, nela se trabalha com o enriquecimento curricular.

A escola pode contribuir muito para o desenvolvimento dos alunos com $\mathrm{AH} / \mathrm{SD}$, desenvolvendo projetos que atendam suas necessidades e contribuam para o desenvolvimento de suas potencialidades e habilidades.

O professor da sala do ensino regular comum, também deve trabalhar com atividades de enriquecimento curricular, porque estas irão proporcionar ao aluno com $\mathrm{AH} / \mathrm{SD}$ e também aos seus colegas de sala o ampliação de conhecimentos além do currículo escolar.

Importante pontuar que toda intervenção e/ou aceleração curricular no ambiente escolar, deve ser realizado em parceria com uma equipe de profissionais da educação, porque o indivíduo pode ter habilidade em uma área específica e em outras apresentar as limitações normais de qualquer outra pessoa.

Um pensamento errôneo sobre a pessoa com altas habilidades/ superdotação é de que eles podem desenvolver suas habilidades sem precisar de ajuda educacional. Na verdade os alunos com altas habilidades/ 
superdotação necessitam do ambiente social e educacional para o seu desenvolvimento, ou seja, precisam de uma gama de experiências enriquecedoras que estimulem seu potencial.

\section{ESTATÍSTICA DAS ALTAS HABILIDADES E SUPER DOTAÇÃO}

Segundo informações obtidas junto ao Núcleo Regional de Educação de Umuarama, nos documentos consultados constam dados de 14 cidades e 53 colégios, conforme Figura 1, que fizeram a indicação de alunos com altas habilidades e super dotação para que fosse verificada se os mesmos são diagnosticados com AH/SD.

Figura 1: Cidades e Colégios objeto de estudos

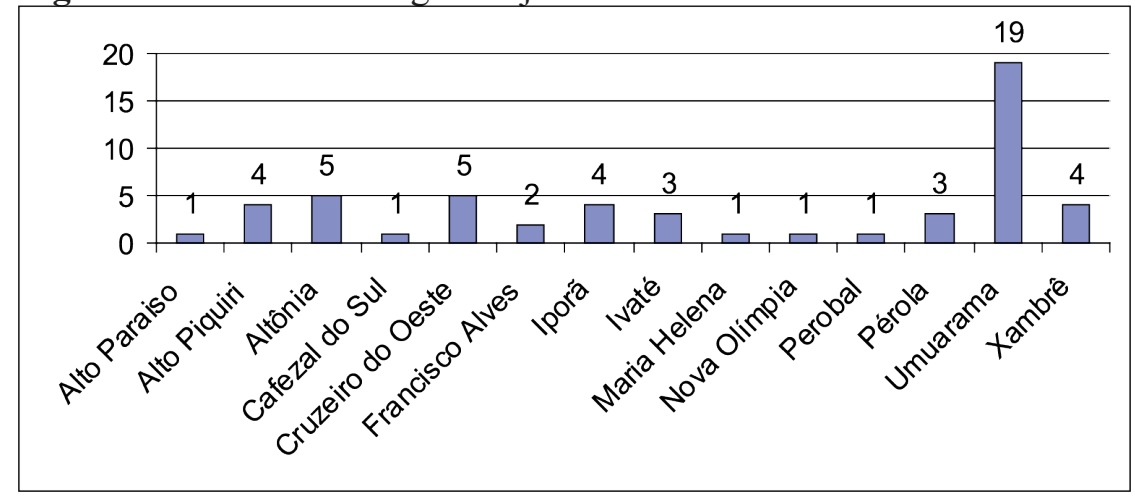

Fonte: NRE - Umuarama

No total de alunos indicados para aplicação do diagnóstico de $\mathrm{AH} / \mathrm{SD}$, verificou-se que existe uma proximidade bem acentuada entre o sexo masculino e feminino, entre as fichas catalogadas, consta que 4 alunos foram indicados para realizar o diagnóstico mas não foi identificado se eram meninos ou meninas (Figura 2). 
Figura 2: Sexo

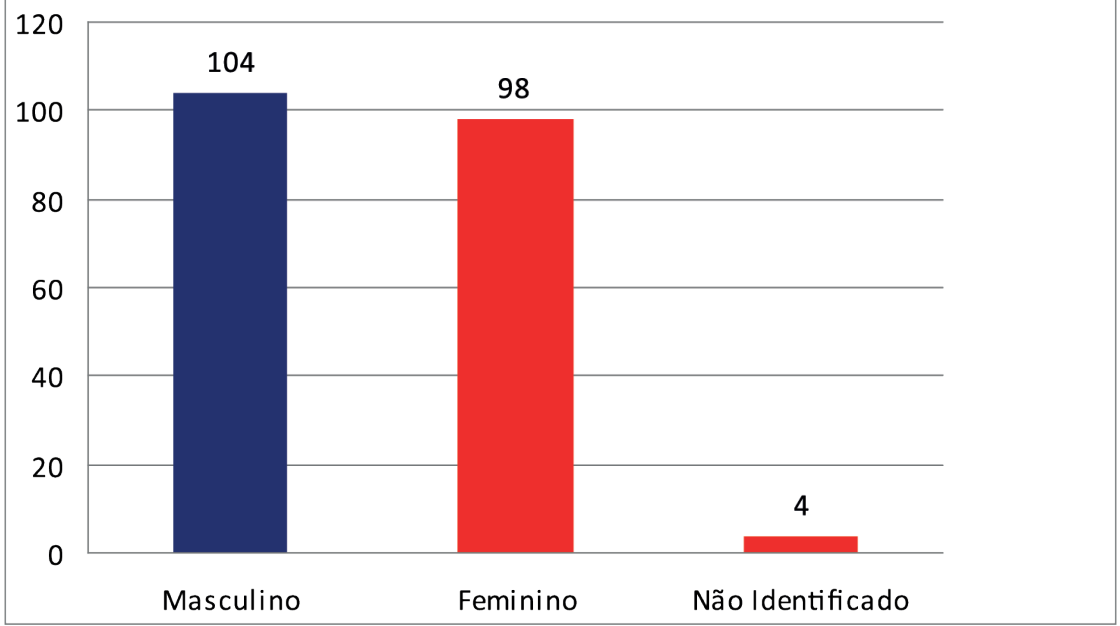

Fonte: NRE - Umuarama

Nos documentos fornecidos pelo Núcleo Regional de Educação de Umuarama, os alunos indicados para o diagnóstico estão matriculados do $1^{\circ}$ ao $9^{\circ}$ ano, sendo o $2^{\circ}$ ano o que mais teve alunos indicados (36) para o diagnóstico seguido da $1^{\circ}$ e $3^{\circ}$ com 32 alunos indicados, o $5^{\circ}$ ano com 30 e o $6^{\circ}$ ano com 25 . As demais séries apresentaram total de alunos abaixo de 20 indicações. 
Figura 3: Série

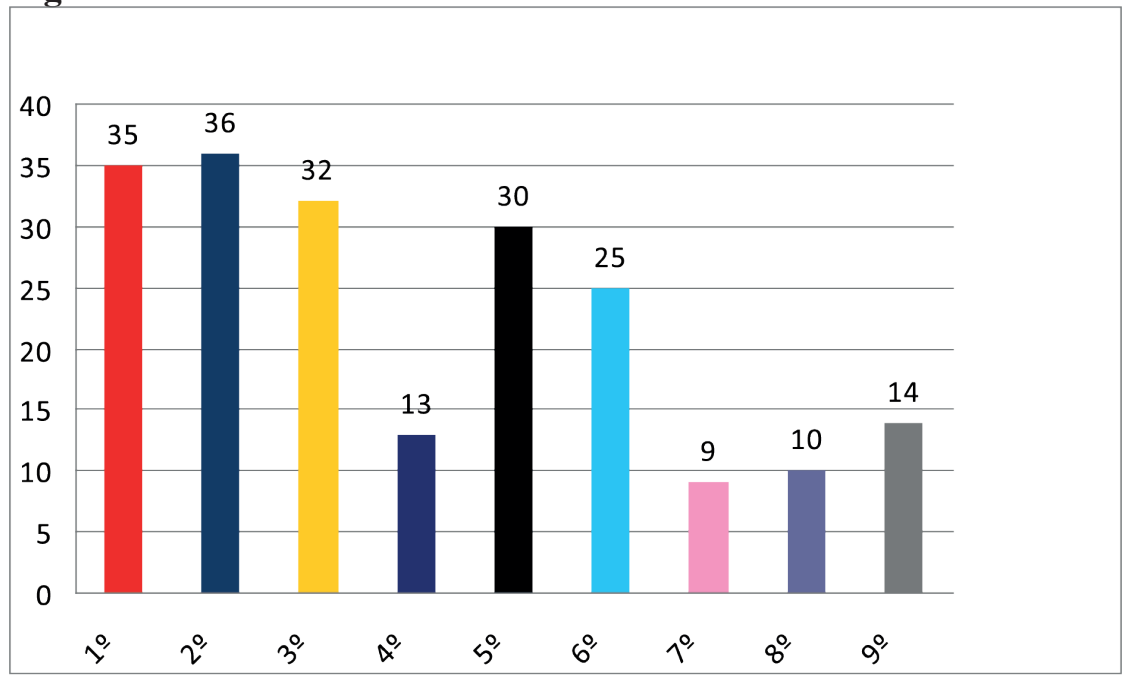

Fonte: NRE - Umuarama

Na Cidade de Umuarama no Colégio Estadual Monteiro Lobato aplicou-se os testes no $6^{\circ}$ ano " $C$ ", com 29 alunos, não houve indicadores para as AH / SD, o mesmo ocorreu em duas escolas na Cidade de Alto Piquiri, na Escola Municipal Governador Parigot de Souza, aplicou-se os testes no $4^{\circ}$ ano, com média de 20 alunos, na Escola Municipal Luiz Sibirino Moura aplicou-se os testes no $3^{\circ}$ ano, com média de 20 alunos, e Não identificou nenhum aluno para AH/SD.

Conforme informação do Núcleo Regional de Educação de Umuarama, de todos os alunos pré-avaliados com indicação de $\mathrm{AH} / \mathrm{SD}$, não foi realizado a avaliação diagnóstica por falta de profissionais especializados na área.

No Núcleo Regional de Educação de Umuarama, existem duas (02) salas para atendimento educacional especializado em Altas Habilidades e Superdotação sendo uma no município de Umuarama, funcionando no Colégio Estadual Monteiro Lobato e uma no município de Iporã, funcionando no Colégio Estadual de Iporã. 


\section{CONCLUSÃO}

Na pesquisa realizada pelos professores regentes de sala dos alunos matriculados entre o $1^{\circ}$ e $9^{\circ}$ anos nos colégios pertencentes ao NRE de Umuarama, 204 alunos obtiveram indicação para avaliação em AH/ SD.

Conforme dados coletados, existem várias crianças com indicadores de altas habilidades e superdotação, mas por falta de profissionais habilitados, os órgãos responsáveis, não conseguiram concluir a realização das avaliações/diagnósticos e a indicação para as salas de recursos multifuncional Tipo I específics em AH/SD.

Com este resultado percebe-se que muitos alunos poderiam ter um atendimento especializado e avançar em seus estudos, principalmente na iniciação científica, enquanto que muitos recebem atendimento escolar básico. Dessa maneira, muitos talentos são desperdiçados, pela falta de confirmação do diagnóstico.

Nos dados levantados obteve-se que existem duas (02) salas para atendimento educacional especializado em Altas Habilidades e Superdotação sendo uma no município de Umuarama, funcionando no Colégio Estadual Monteiro Lobato e uma no município de Iporã, funcionando no Colégio Estadual de Iporã. Estes dados demonstram que seria necessário aumentar a quantidade de salas de Recursos para melhor atendimento dos alunos diagnosticados com $\mathrm{AH} / \mathrm{SD}$.

\section{REFERÊNCIAS}

ALVES, D. de O.; GOTTI, M. de O. Atendimento Educacional

Especializado - Concepção, princípios e aspectos organizativos. In. BRASIL. III Seminário Nacional de formação de gestores e educadores: Ensaios Pedagógicos. MEC/SEESP: Brasília/DF, 2006.

BRASIL. Ministério da Educação/Secretaria de Educação Especial. Resolução CNE/CEB n ${ }^{\text {2 }}$, de 11 de Setembro de 2001. Institui Diretrizes Nacionais para a Educação Especial na Educação Básica. Brasília, DF. Disponível em < http://portal.mec.gov.br/cne/arquivos/pdf/ CEB0201.pdf $>$ Data de acesso: 11 de jul, 2014. 
. Ministério da Educação/Secretaria de Educação Especial.

Documento Subsidiário à Política da Inclusão. Brasília: MEC/SEESP, 2005. Disponível em: <www.mec.gov.br/seesp>. Data de acesso: 06 de out, 2014.

. Ministério da Educação/Secretaria de Educação Especial.

Política Nacional de Educação Especial na Perspectiva da Educação Inclusiva. Brasília: MEC/SEESP, 2007. Disponível em: < http://peei. mec.gov.br/arquivos/politica_nacional_educacao_especial.pdf $>$. Data de acesso: 06 out 2014.

CARVALHO, Rosita Edler. Educação inclusiva: com os pingos nos "is". 4. ed. Porto Alegre: Ed. Meditação, 2006.

FLEITH, Denise de Souza. A Construção de Práticas Educacionais para Alunos com Altas Habilidades / Superdotação. Volume 1:

Orientação a Professores. Brasília, DF: MEC/SAESP, 2007.

GUENTHER, Zenita. Desenvolver capacidades e talentos: um conceito de inclusão. Petrópolis, RJ: Vozes, 2000.

MAKISHIMA, Édne Aparecida Claser. ZAMPRONI, Eliete Cristina Berti. Transtornos Funcionais Especificos. Secretaria de Estado da Educação Superintendência de Estado da Educação Departamento de Educação Especial e Inclusão Educacional. Material do curso de formação de professores. Curitiba, 2013

TEIXEIRA, Gustavo. Transtornos Comportamentais na Infância e Adolescência. São Paulo: Rubio, 2006.

CIASCA, S. M. Distúrbio de Aprendizagem: proposta de avaliação disciplinar. São Paulo: Casa do Psicólogo, 2003.

GAlVÃO FILHO, T. A. DAMASCENO, L. L. As Novas Tecnologias e as Tecnologias Assistivas: Utilizando os Recursos de Acessibilidade na Educação. Anais do III Congresso Ibero-Americano de Informática na Educação Especial, Fortaleza, MEC, 2002. Disponível em $<$ http://www. planetaeducacao.com.br/portal/artigo.asp? artigo $=622>$ Data de acesso: 
04 out 2014 .

VYGOTSKY, L. S. A formação social da mente. 3 ed. São Paulo: Martins Fontes, 1989.

VYGOTSKY, L. S. Pensamento e da linguagem. Tradução de Jéferson Luiz Camargo. São Paulo: Martins Fontes, 2000.

VYGOTSKY, L. S.; LURIA, A. R. Estudos sobre a história do comportamento: Símios, homem primitivo e criança. Porto Alegre: Artmed, 1996.

ZAMPRONI, E. C. B. Conceituando a deficiência intelectual. Curso de formação em Educação Especial. Moodle: e-escola. Secretaria de Estado da Educação do Paraná. 2012.

Recebido em: 25/05/2017

Aprovado em: 20/07/2017 